\title{
Prevalence of gastric cancer precursors in gastroscopy-screened adults by family history of gastric cancer and of cancers other than gastric
}

Rui $\mathrm{Wu}^{1,2+}$, Cheng Yang ${ }^{1 \dagger}$, Lin $\mathrm{Ji}^{1}$, Zhi-Ning Fan ${ }^{2}$, Yu-Wen Tao ${ }^{2}$ and Qiang Zhan ${ }^{1 *}$

\begin{abstract}
Background: People are at a high risk of gastric cancer if their first-degree relatives suffered from atrophic gastritis (AG), intestinal metaplasia (IM), intraepithelial neoplasia (IEN), dysplasia (DYS), or gastric cancer (GC). This study was performed to analyse the association between FDR-GC and GC precursors.

Methods: A cross-sectional study was performed to screen the prevalence of GC precursors from November 2016 to September 2019. A total of 1329 participants with FDR-GC, 193 participants with a family history of non-gastric cancer in FDRs (FDR-nGC), and 860 participants without a family history of cancer in FDRs (FDR-nC) were recruited in this study. The logistic regression model was used in this study.

Results: The prevalence of normal, Non-AG, AG/IM, IEN/DYS, and GC was 31.91, 44.21, 13.81, 8.73, and 1.34\%, respectively. The prevalence of IEN/DYS was higher in people with FDR-GC and FDR-nGC (FDR-GC: odds ratio $(\mathrm{OR})=1.655 ; 95 \% \mathrm{Cl}, 1.153-2.376 ; \mathrm{FDR}-\mathrm{nGC}: \mathrm{OR}=1.984 ; 95 \% \mathrm{Cl}, 1.122-3.506)$ than those with FDR-nC. The younger the age at which FDRs were diagnosed with $G C$, the more likely the participants were to develop $A G / I M\left(P_{\text {trend }}=\right.$ 0.019). The risk of precursors to GC was higher in participants whose FDR-GC was the mother than in those whose FDR-GC was the father or sibling (OR, non-AG: 1.312 vs. 1.007, 1.274; AG/IM: 1.430 vs. 1.296, 1.378; IEN/DYS: 1.988 vs. $1.573,1.542)$. There was no statistically significant difference in non- $A G(O R=1.700 ; 95 \% \mathrm{Cl}, 0.940-3.074)$, AG/IM $(\mathrm{OR}=1.291 ; 95 \% \mathrm{Cl}, 0.579-2.877)$, and IEN/DYS $(\mathrm{OR}=1.265 ; 95 \% \mathrm{Cl}, 0.517-3.096)$ between participants with one or more FDR-GC.

Conclusion: People with FDR-GC and FDR-nGC are at a high risk of IEN/DYS. When an FDR was diagnosed at a younger age, the risk of AG/IM was higher. The risk of GC precursors was higher in people whose FDR-GC was the mother.
\end{abstract}

Keywords: Family history, First-degree relative, Gastric precancerous lesions, Pathology

\footnotetext{
* Correspondence: ryzhanqiang@163.com

${ }^{\dagger}$ Rui Wu and Cheng Yang contributed equally to this work.

'Department of Gastroenterology, The Affiliated Wuxi People's Hospital to Nanjing Medical University, 299 Qingyang Road, Wuxi 214023, Jiangsu, China Full list of author information is available at the end of the article
}

(c) The Author(s). 2020 Open Access This article is licensed under a Creative Commons Attribution 4.0 International License, which permits use, sharing, adaptation, distribution and reproduction in any medium or format, as long as you give appropriate credit to the original author(s) and the source, provide a link to the Creative Commons licence, and indicate if changes were made. The images or other third party material in this article are included in the article's Creative Commons licence, unless indicated otherwise in a credit line to the material. If material is not included in the article's Creative Commons licence and your intended use is not permitted by statutory regulation or exceeds the permitted use, you will need to obtain permission directly from the copyright holder. To view a copy of this licence, visit http://creativecommons.org/licenses/by/4.0/. The Creative Commons Public Domain Dedication waiver (http://creativecommons.org/publicdomain/zero/1.0/) applies to the data made available in this article, unless otherwise stated in a credit line to the data. 


\section{Background}

Gastric cancer (GC) is associated with high incidence and mortality worldwide, especially in China, Japan, and Korea [1]. Gastric cancer has been a global health problem for a long time, with more than 1 million new cases and an estimated 783,000 deaths in 2018 all around the world [2]. Despite incidence and mortality of gastric cancer have decreased over the past 5 decades, gastric cancer remains the third leading cause of cancer-related death [3]. Meanwhile, the gastric cancer has three histological subtypes according to the Laurén classification (intestinal, diffuse and mixed type). Between 1989 and 2015, the relative median survival of non-metastatic intestinal and diffuse type gastric cancer improved from 22.8 to 27.6 months, and from 16.8 to 18.0 months, respectively [4]. The evidence was accumulated that the intestinal type of gastric cancer develops through a sequence of non-atrophic gastritis, atrophy, intestinal metaplasia, and dysplasia (intraepithelial neoplasia) to gastric cancer. However, the natural history of diffuse gastric cancer is unclear [5]. All these histological subtypes were relevant to our investigation.

Early detection of GC via screening endoscopy in asymptomatic patients enhances patient outcomes, especially in high-risk populations [6]. A Korean study [7] showed a 47\% reduction in mortality after patients with GC underwent gastroendoscopy screening, and a 30\% reduction was reported in Japan [8]. In China, a population-based study showed that people who underwent gastroendoscopy had a $28 \%$ reduced risk of mortality from GC [9]. However, compared to the large population in China, professionals and facilities are relatively limited, and we can now only screen individuals who are at a high risk of GC [10].

A family history of GC in first-degree relatives (FDRs) is one of the most important risk factors for $\mathrm{GC}[11,12]$. It has been reported that when the gastric lesions of FDRs change from a normal to precancerous status, and finally to $\mathrm{GC}$, the incidence of $\mathrm{GC}$ in individuals increases significantly $\left(7.7 \times 10^{-5}\right.$ year $^{-1}, 11.2$ to $12.6 \times$ $10^{-5}$ year $^{-1}$, and $18.4 \times 10^{-5}$ year $^{-1}$, respectively) [13]. Meanwhile, some studies have reported that a family history of cancer in FDRs not only increases the risk of GC, but also increases the risk of gastric atrophy [14], which is an important precursor of GC [15]. In addition, patients with intestinal metaplasia have a significantly increased risk of GC [16]. However, there are few detailed reports of changes in gastric pathology in individuals with a family history of FDR-GC. Therefore, this study was conducted to examine in detail the gastric pathology of individuals with a family history of GC and provide a basis for screening of people at a high risk of GC.

\section{Methods}

From November 2016 to September 2019, a crosssectional study was performed to screen the prevalence of GC precursors. A total of 19,879 patients were given the serological tests, and 2382 patients underwent endoscopy and histopathological assessment.

The study protocol was reviewed and approved by the Ethics Committee of Wuxi People's Hospital. All procedures performed in this study were in accordance with the ethical standards of the institutional and national research committee and the 1964 Declaration of Helsinki and its later amendments or comparable ethical standards. Each participant provided signed informed consent prior to enrolment.

\section{Study population}

From November 2016 to November 2017, the first stage of the screening study at our digestive endoscopy centre was conducted by combining serological tests (pepsinogen and HP) with a family history of GC, and it was found that people with FDR-GCs had a higher gastroscopy screen-detected prevalence of GC [10]. In this stage, 7773 participants were serologically tested, and 872 underwent endoscopy and biopsy from 19,881 registered residents aged 40 to 69 years $[17,18]$ in seven communities in the Xinwu District of Wuxi City, Jiangsu Province, China. These seven communities were randomly selected from all 68 geographic communities in Xinwu District, and encompassed diverse areas.

From February 2018 to September 2019, the second stage of the screening study was performed using the same process, which was based on serological tests (pepsinogen and HP) and family history of GC. In these two stages, 50,063 registered residents aged 40 to 69 years from the same seven communities were recruited. Of these, 31,508 were willing to participate in the study, and participants with a history of developed cancer; gastric surgery, including endoscopic submucosal dissection or endoscopic mucosal resection; coagulopathy; and serious cardiopulmonary, liver, kidney, or psychiatric disorders; or those who failed to provide written informed consent were excluded from the study. Participants assured the researchers that they had not taken an acid suppressant or gastro-protective agent within the previous two weeks to prevent interference with levels of pepsinogen (PG), and also had not taken an antiplatelet drug such as aspirin to prevent bleeding during the endoscopic biopsy. Ultimately, 19,879 participants met the inclusion criteria, and fasting blood samples were collected for serological tests, including PGI, PGII, PGR, and anti-HP IgG. People who were positive for PG were all recruited for the study, and those who were negative for $\mathrm{PG}$ were recruited randomly. The $\mathrm{PG}^{-}: \mathrm{PG}^{+}$ratio was $3: 1$ and it was stratified by H.pylori status. Further, this selection process resulted in intended participants comprising $74.1 \%$ of all participants in the $\mathrm{PG}^{+}$group and $10.8 \%$ of those in the $\mathrm{PG}^{-}$group. The remaining 


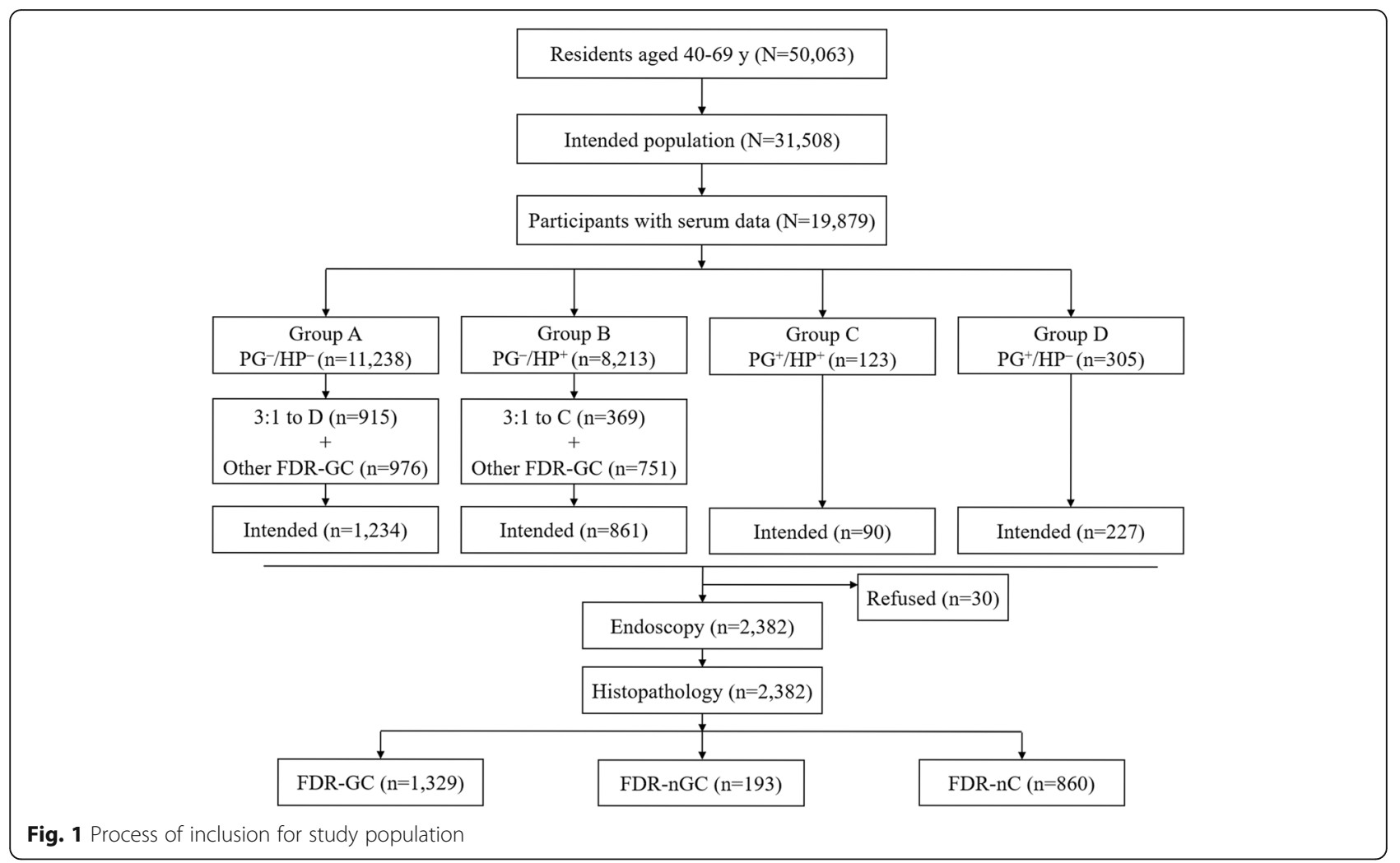

individuals with FDR-GC among 19,879 eligible participants were all recruited for the study as well (Fig. 1).

Ultimately, in two stages of the screening study, 1329 participants with FDR-GC, 193 participants with a family history of non-gastric cancer in first-degree relatives (FDR-nGC), and 860 participants without a family history of cancer in first-degree relatives (FDR-nC) underwent gastroendoscopy and histopathological assessment.

\section{Data collection}

Information on sex, age, height (centimetres), weight (kilograms), family history of cancer, smoking (ever or never), drinking (ever or never), tea consumption (present or absent), intake of fruit and vegetables ( $<3$ times/week or $\geq 3$ times/week), and high-salt diet (present or absent) was collected from participants using self-assessment questionnaires. A positive family history was defined as a family history of cancer in the father, mother, sibling, or child of a participant. Participants with a positive family history were asked to provide cancer type and the age at diagnosis for each affected relative.

Fasting blood samples of the participants were collected for serological tests. PGI and PGII quantitative determination kits (Wuxi Jiangyuan Industrial Technology and Trade, Wuxi, Jiangsu, China) were used to examine the levels of PGI, PGII, and PGR via timeresolved fluoroimmunoassay in accordance with the manufacturer's protocols. Atrophic serum PG $\left(\mathrm{PG}^{+}\right)$was defined as $\mathrm{PGI}<60 \mathrm{ng} / \mathrm{mL}$ and $\mathrm{PGR}<6.0$, and the remaining population was defined as normal serum PG $\left(\mathrm{PG}^{-}\right)$in accordance with the manufacturer's protocol. An HP antibody diagnostic test kit (Assure Tech, Hangzhou, Zhejiang, China) was provided to examine anti-HP IgG using a colloidal gold assay in accordance with the manufacturer's manual. The details of the serological tests have been previously reported [19].

Twenty gastroenterologists each with more than 5 years of experience performed endoscopic procedures in 2382 participants. In every case, the gastric mucosa in the gastric antrum and gastric corpus was clipped for biopsy. Gastric mucosal biopsies were assessed in accordance with the standard criteria from the World Health Organization for the classification of GC and the updated Sydney System for grading and classification of gastritis by two expert gastrointestinal pathologists [20, 21]. Each participant who underwent gastroendoscopy and histopathological assessment was assigned a diagnosis of the gastric antrum, gastric corpus, and the whole stomach (including gastric antrum, gastric corpus, gastric angle, and gastric cardia). The diagnoses included normal, non-atrophic gastritis, atrophic gastritis/intestinal metaplasia, intraepithelial neoplasia/dysplasia, and GC.

\section{Statistical analysis}

Analyses of demographic and clinical data were performed using SPSS software 21.0 version (IBM Corp, 
Armonk, NY, USA). We expressed the categorical variables as frequencies and percentages and the continuous variables as means \pm standard deviations. Baseline characteristics were analysed using the chi-square test for categorical variables (sex, HP, family history, smoking, drinking, high-salt diet, tea, fruit/vegetables, and stage I and II) and analysis of variance for continuous variables (age, PGI/II, and BMI). A multinomial logistic regression model was used to analyse the pathological differences among FDR-GC, FDR-nGC, and FDR-nC. Pathological results were used as outcome variables (excluding the population diagnosed with GC $(N=32)$ ), and the pathological results of the normal cases were used as the reference group. Odds ratios (ORs) and 95\% confidence intervals (CIs) were calculated, and the level of statistical significance was set at $P<0.05$.

\section{Results}

\section{Characteristics of participants with different gastric} pathologies

In this study, it was found that family history significantly affected gastric pathology $(P=0.019)$. Moreover, sex $(P<0.001)$, age $(P<0.001)$, HP $(P<0.001)$, PGR $(P<$ $0.001)$, smoking $(P<0.001)$, drinking $(P=0.002)$, and tea consumption $(P=0.011)$ were closely related to gastric pathologies.

In addition, the gastric pathologies of the four groups in two stages are reported in Table 1. A total of $32 \mathrm{pa}-$ tients with GC and 208 patients with intraepithelial neoplasia/dysplasia was detected in these two stages.

\section{Pathological distribution in the gastric antrum, gastric corpus, and whole stomach}

In the whole stomach (including gastric antrum, gastric corpus, gastric angle, and gastric cardia) of participants with FDR-GC, the proportion of atrophic gastritis/intestinal metaplasia ( $14.30 \%$ vs. $13.49 \%)$, intraepithelial neoplasia/dysplasia $(9.48 \%$ vs. $6.74 \%)$, and GC $(1.50 \%$ vs. $1.40 \%)$ was higher than that in participants with FDR$\mathrm{nC}$, while the proportion of normal and non-atrophic gastritis in participants with FDR-GC was lower $(P=$ 0.021). Additionally, the proportion of intraepithelial neoplasia/dysplasia (12.44\% vs. $6.74 \%$ ) in participants with FDR-nGC was higher than that in participants with FDR-nC, while the proportion of normal, non-atrophic gastritis, and atrophic gastritis/intestinal metaplasia in participants with FDR-GC was lower $(P=0.027)$. However, none of the participants with FDR-nGC were diagnosed with GC. In addition, the pathological distribution of the gastric antrum was significantly different in patients with FDR-GC, FDR-nGC, and FDR-nC $(P=0.001)$, but there was no significant difference in the gastric corpus $(P=0.689)$ (Fig. 2).

\section{Characteristics of participants with FDR-nC, FDR-nGC, and} FDR-GC

There were significant differences in sex $(P<0.001)$, age $(P<0.001)$ and HP $(P<0.001)$ among participants with FDR-nC, FDR-nGC, and FDR-GC. At the same time, some lifestyle factors, such as smoking $(P<0.001)$, drinking $(P<0.001)$, and tea consumption $(P<0.001)$, also have significant differences for people in three groups (Table 2).

\section{Gastric pathologies of people with a family history of cancer}

People with a FDR-GC and FDR-nGC had higher prevalences of intraepithelial neoplasia/dysplasia compared to those with no family history of cancer in the whole stomach $(9.48 \%$ vs. $6.74 \%$ OR $=1.655 ; 95 \% \mathrm{CI}, 1.153-$ 2.376 and $12.44 \%$ vs. $6.74 \%$ OR $=1.984$; $95 \%$ CI, $1.122-$ 3.506), respectively. Meanwhile, people with a FDR-GC had higher prevalence of atrophic gastritis/intestinal metaplasia compared to those with no family history of cancer, especially in the gastric antrum $(11.06 \%$ vs. 9.53\% OR $=1.426$; $95 \% \mathrm{CI}, 1.038-1.959)$. In addition, a family history of cancer did not significantly affect the gastric corpus. The OR value was adjusted by sex, age, $\mathrm{HP}$, smoking, drinking, high-salt diet, and tea consumption. The findings for the gastric antrum, gastric corpus, and the whole stomach are reported in Table 3 and Table 4.

\section{Influence of age at diagnosis of GC in FDRs on participants' gastric pathologies}

Among the 1309 participants with FDR-GC (20 patients diagnosed with GC were excluded), 1047 participants had a single FDR with only GC and no other cancer. Of the 1047 participants, 42 were unable to identify their age at diagnosis, while the remaining 1005 were included in the study. This avoided the confounding factors of type and number of people with a family history of cancer. The younger the FDRs were at the time of GC diagnosis, the more likely the participants were to develop atrophic gastritis/intestinal metaplasia (OR: < 50: 4.921; $\geq 50$ : 3.410 ; $\geq 60: 3.239$; $\geq 70: 2.898$; $\geq 80$ : $1 ; P_{\text {trend }}=0.019$ ), but this trend was not significant in people with nonatrophic gastritis (OR: <50: 2.185; $\geq 50: 1.098 ; \geq 60$ : $\left.1.202 ; \geq 70: 1.210 ; \geq 80: 1 ; P_{\text {trend }}=0.217\right)$ and intraepithelial neoplasia/dysplasia (OR: $<50: 2.372$; $\geq 50: 1.039$; $\geq 60$ : $\left.1.517 ; \geq 70: 1.578 ; \geq 80: 1 ; P_{\text {trend }}=0.823\right)$. The OR value was adjusted by sex, age, HP, smoking, drinking, highsalt diet, and tea consumption (Table 5).

Influence of a FDR-GC who was the father, mother, or sibling on gastric pathology of the participants Of the 1309 participants with FDR-GC (20 patients diagnosed with GC were excluded), 1047 participants had a 
Table 1 Characteristics of participants with different gastric pathologies

\begin{tabular}{|c|c|c|c|c|c|c|}
\hline & Normal & Non-AG & $A G / I M$ & IEN/DYS & GC & $P$ \\
\hline Overall & 760(31.91\%) & 1053(44.21\%) & $329(13.81 \%)$ & 208(8.73\%) & $32(1.34 \%)$ & \\
\hline Family History & & & & & & 0.019 \\
\hline FDR-GC & 394(29.65\%) & 599(45.07\%) & 190(14.30\%) & $126(9.48 \%)$ & $20(1.50 \%)$ & \\
\hline FDR-nGC & $59(30.57 \%)$ & $87(45.08 \%)$ & 23(11.92\%) & $24(12.44 \%)$ & $0(0.00 \%)$ & \\
\hline FDR-nC & 307(35.70\%) & $367(42.67 \%)$ & 116(13.49\%) & $58(6.74 \%)$ & $12(1.40 \%)$ & \\
\hline Sex & & & & & & $<0.001$ \\
\hline Male & 287(29.77\%) & 412(42.74\%) & 127(13.17\%) & 117(12.14\%) & $21(2.18 \%)$ & \\
\hline Female & 473(33.36\%) & $641(45.20 \%)$ & $202(14.25 \%)$ & $91(6.42 \%)$ & $11(0.78 \%)$ & \\
\hline Age & $57.92 \pm 7.70$ & $58.62 \pm 7.52$ & $60.05 \pm 7.16$ & $61.19 \pm 6.33$ & $62.50 \pm 5.70$ & $<0.001$ \\
\hline $\mathrm{HP}$ & & & & & & $<0.001$ \\
\hline Positive & $121(12.89 \%)$ & $540(57.51 \%)$ & 165(17.57\%) & $95(10.12 \%)$ & 18(1.92\%) & \\
\hline Negative & 639(44.28\%) & $513(35.55 \%)$ & 164(11.37\%) & 113(7.83\%) & $14(0.97 \%)$ & \\
\hline$P G \mid / I I$ & $16.39 \pm 7.41$ & $12.78 \pm 6.37$ & $12.84 \pm 7.13$ & $13.68 \pm 6.97$ & $13.96 \pm 11.56$ & $<0.001$ \\
\hline Smoking & & & & & & $<0.001$ \\
\hline Ever & $171(27.58 \%)$ & $261(42.10 \%)$ & $82(13.23 \%)$ & $90(14.52 \%)$ & $16(2.58 \%)$ & \\
\hline Never & 589(33.43\%) & 792(44.95\%) & $247(14.02 \%)$ & 118(6.70\%) & 16(0.91\%) & \\
\hline Drinking & & & & & & 0.002 \\
\hline Ever & 134(28.94\%) & 208(44.92\%) & $53(11.45 \%)$ & $57(12.31 \%)$ & $11(2.38 \%)$ & \\
\hline Never & 626(32.62\%) & $845(44.03 \%)$ & 276(14.38\%) & $151(7.87 \%)$ & 21(1.09\%) & \\
\hline High-Salt Diet & & & & & & 0.699 \\
\hline Present & 606(31.50\%) & 859(44.65\%) & 262(13.62\%) & 169(8.78\%) & $28(1.46 \%)$ & \\
\hline Absent & 154(33.62\%) & 194(42.36\%) & $67(14.63 \%)$ & $39(8.52 \%)$ & $4(0.87 \%)$ & \\
\hline Tea & & & & & & 0.011 \\
\hline Present & $301(30.75 \%)$ & 433(44.23\%) & $123(12.56 \%)$ & 103(10.52\%) & 19(1.94\%) & \\
\hline Absent & 459(32.72\%) & 620(44.19\%) & 206(14.68\%) & 105(7.48\%) & 13(0.93\%) & \\
\hline BMI & $23.79 \pm 2.88$ & $24.51 \pm 17.04$ & $23.79 \pm 2.97$ & $23.81 \pm 2.81$ & $23.76 \pm 3.08$ & 0.687 \\
\hline Fruit/Negetables & & & & & & 0.760 \\
\hline$\geq 3$ Times/Week & 487(32.08\%) & 669(44.07\%) & 209(13.77\%) & 136(8.96\%) & $17(1.12 \%)$ & \\
\hline$<3$ Times/Week & 273(31.60\%) & 384(44.44\%) & 120(13.89\%) & $72(8.33 \%)$ & 15(1.74\%) & \\
\hline Stage I & & & & & & $<0.001$ \\
\hline Group A & 158(38.16\%) & 154(37.20\%) & $63(15.22 \%)$ & $35(8.45 \%)$ & $4(0.97 \%)$ & \\
\hline Group B & $9(2.73 \%)$ & 192(58.18\%) & $75(22.73 \%)$ & $47(14.24 \%)$ & $7(2.12 \%)$ & \\
\hline Group C & $3(7.50 \%)$ & 23(57.50\%) & $9(22.50 \%)$ & $5(12.50 \%)$ & $0(0.00 \%)$ & \\
\hline Group D & $8(9.09 \%)$ & $42(47.73 \%)$ & $22(25.00 \%)$ & 13(14.77\%) & $3(3.41 \%)$ & \\
\hline Stage II & & & & & & $<0.001$ \\
\hline Group A & $407(50.56 \%)$ & 268(33.29\%) & 67(8.32\%) & $57(7.08 \%)$ & $6(0.75 \%)$ & \\
\hline Group B & $95(18.13 \%)$ & $304(58.02 \%)$ & $74(14.12 \%)$ & $41(7.82 \%)$ & 10(1.91\%) & \\
\hline Group C & 14(31.11\%) & $21(46.67 \%)$ & $7(15.56 \%)$ & $2(4.44 \%)$ & $1(2.22 \%)$ & \\
\hline Group D & $66(48.53 \%)$ & 49(36.03\%) & 12(8.82\%) & $8(5.88 \%)$ & $1(0.74 \%)$ & \\
\hline
\end{tabular}

Abbreviations: $A G$ atrophic gastritis, IM intestinal metaplasia, IEN intraepithelial neoplasia, DYS dysplasia, GC gastric cancer

Stage I, the study from November 2016 to November 2017 at our digestive endoscopy center; Stage I, the study from February 2018 to September 2019 at our digestive endoscopy center. Group A: people with $\mathrm{PG}^{-}$and $\mathrm{HP}^{-}$; Group B: people with $\mathrm{PG}^{-}$and $\mathrm{HP}^{+}$; Group C: people with $\mathrm{PG}^{+}$and $\mathrm{HP}^{+}$; Group D: people with $\mathrm{PG}^{+}$and $\mathrm{HP}^{-}$ 


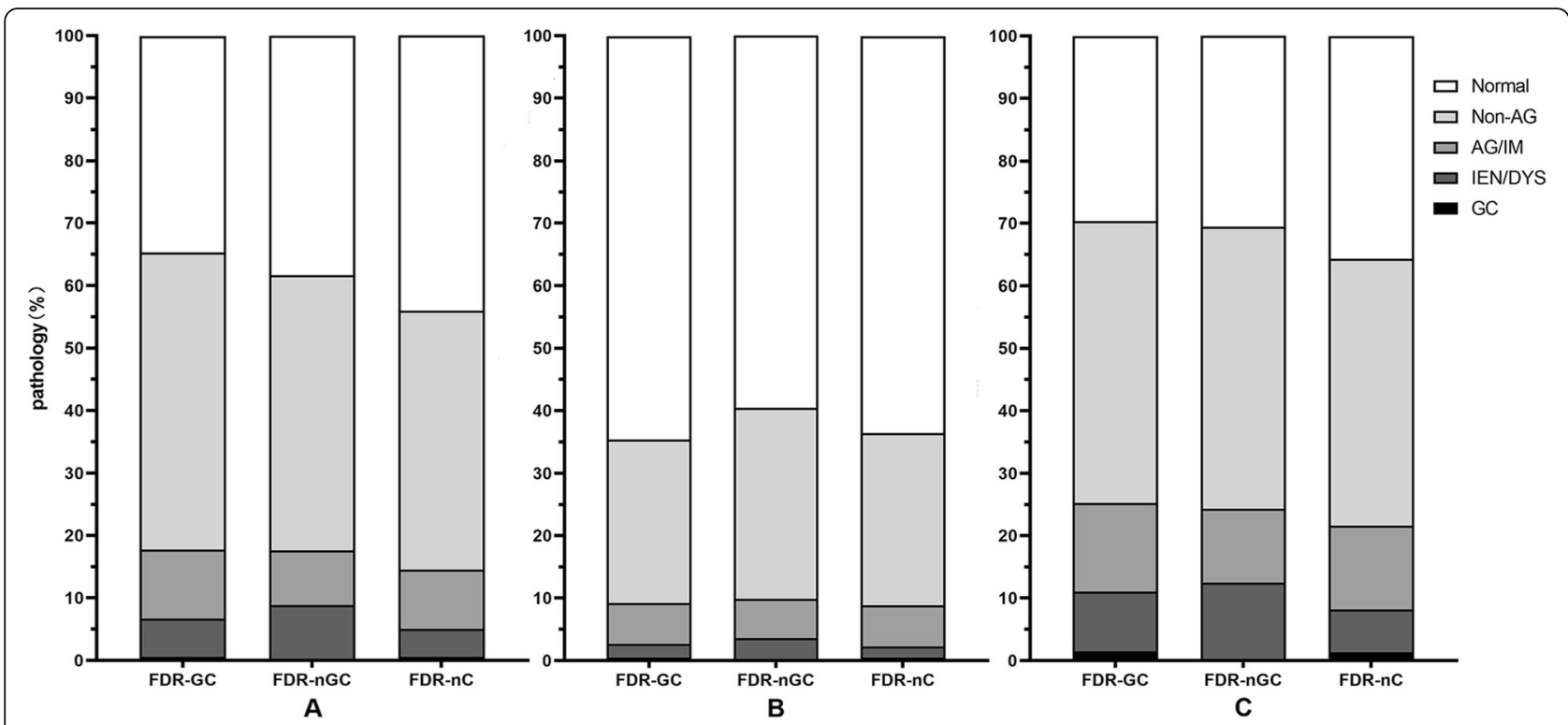

Fig. 2 Pathological distribution in gastric antrum, gastric corpus and the whole stomach. a, gastric antrum; b, gastric corpus; $\mathbf{c}$, the whole stomach. Abbreviations: AG, atrophic gastritis; IM, intestinal metaplasia; IEN, intraepithelial neoplasia; DYS, dysplasia; GC, gastric cancer

Table 2 Characteristics of participants with FDR-nC, FDR-nGC, and FDR-GC

\begin{tabular}{|c|c|c|c|c|}
\hline & FDR-nC & FDR-nGC & FDR-GC & $P$ \\
\hline Sex & & & & $<0.001$ \\
\hline Male & $281(32.67 \%)$ & $81(41.97 \%)$ & $602(45.3 \%)$ & \\
\hline Female & 579(67.33\%) & 112(58.03\%) & 727(54.7\%) & \\
\hline Age & $59.98 \pm 7.35$ & $60.81 \pm 6.92$ & $57.87 \pm 7.5$ & $<0.001$ \\
\hline $\mathrm{HP}$ & & & & $<0.001$ \\
\hline Positive & 295(34.3\%) & $71(36.79 \%)$ & $573(43.12 \%)$ & \\
\hline Negative & $565(65.7 \%)$ & $122(63.21 \%)$ & $756(56.88 \%)$ & \\
\hline Smoking & & & & $<0.001$ \\
\hline Ever & 170(19.77\%) & $47(24.35 \%)$ & 403(30.32\%) & \\
\hline Never & $690(80.23 \%)$ & 146(75.65\%) & $926(69.68 \%)$ & \\
\hline Drinking & & & & $<0.001$ \\
\hline Ever & $121(14.07 \%)$ & $39(20.21 \%)$ & $303(22.8 \%)$ & \\
\hline Never & 739(85.93\%) & 154(79.79\%) & 1026(77.2\%) & \\
\hline High-Salt Diet & & & & 0.127 \\
\hline Present & 676(78.6\%) & 157(81.35\%) & $1091(82.09 \%)$ & \\
\hline Absent & 184(21.4\%) & $36(18.65 \%)$ & 238(17.91\%) & \\
\hline Tea & & & & $<0.001$ \\
\hline Present & $303(35.23 \%)$ & $84(43.52 \%)$ & $592(44.54 \%)$ & \\
\hline Absent & $557(64.77 \%)$ & 109(56.48\%) & 737(55.46\%) & \\
\hline BMI & $23.65 \pm 2.83$ & $23.79 \pm 2.99$ & $24.45 \pm 15.23$ & 0.270 \\
\hline Fruit/Negetables & & & & 0.313 \\
\hline$\geq 3$ Times/Week & $551(64.07 \%)$ & 132(68.39\%) & $835(62.83 \%)$ & \\
\hline$<3$ Times/Week & 309(35.93\%) & $61(31.61 \%)$ & 494(37.17\%) & \\
\hline
\end{tabular}

single FDR with only GC and no other cancer (the FDRGC of 669 participants was the father; for 235 participants, the FDR-GC was the mother; for 142 participants, the FDR-GC was the sibling; and for one participant, the FDR-GC was a child). A total of 1046 participants whose FDR-GC was the father, mother, or sibling were included in the study. Participants whose FDR-GC was the mother were more likely to suffer from non-atrophic gastritis $(\mathrm{OR}=1.312$; 95\% CI, 0.902-1.907), atrophic gastritis/intestinal metaplasia $(\mathrm{OR}=1.430 ; 95 \% \mathrm{CI}, 0.872$ 2.345), and intraepithelial neoplasia/dysplasia ( $\mathrm{OR}=$ 1.988; 95\% CI, 1.116-3.542) than participants with FDR$\mathrm{nC}$, and the risk was higher than that for participants whose FDR-GC was the father or sibling (non-atrophic gastritis: 1.312 vs. $1.007,1.274$; atrophic gastritis/intestinal metaplasia: 1.430 vs. 1.296, 1.378; intraepithelial neoplasia/dysplasia: 1.988 vs. $1.573,1.542)$. The OR value was adjusted by sex, age, HP, smoking, drinking, high-salt diet, and tea consumption (Table 6).

\section{Influence of one or more FDR-GC on gastric pathology in the participants}

Of the 1309 participants with FDR-GC (20 patients diagnosed with GC were excluded), 1047 participants who had only GC in a single FDR and 81 participants who had only GC in two or more FDRs were included in the study. There was no statistically significant difference in non-atrophic gastritis $(\mathrm{OR}=1.700$; 95\% CI, 0.940-3.074), atrophic gastritis/intestinal metaplasia $(\mathrm{OR}=1.291 ; 95 \%$ CI, 0.579-2.877), and intraepithelial neoplasia/dysplasia $(\mathrm{OR}=1.265$; 95\% CI, 0.517-3.096) between participants with one or more FDR-GC. The OR value was adjusted 
Table 3 Crude odds ratios of whole stomach, gastric antrum and gastric corpus specific GC precursors associated with family history of gastric cancer and of cancers other than gastric

\begin{tabular}{|c|c|c|c|c|c|c|c|c|}
\hline \multirow{2}{*}{$\begin{array}{l}\text { Exposure of interest } \\
\text { Outcome }\end{array}$} & \multicolumn{2}{|c|}{ FDR-nC } & \multicolumn{3}{|c|}{ FDR-GC } & \multicolumn{3}{|c|}{ FDR-nGC } \\
\hline & OR & N (\%) & OR & $95 \% \mathrm{Cl}$ & N (\%) & OR & $95 \% \mathrm{Cl}$ & N (\%) \\
\hline \multicolumn{9}{|l|}{ Gastric Antrum } \\
\hline Non-AG & 1 & 357 (41.51) & 1.466 & $1.214-1.771$ & 635 (47.78) & 1.214 & $0.860-1.712$ & $85(44.04)$ \\
\hline$A G / I M$ & 1 & $82(9.53)$ & 1.467 & $1.083-1.986$ & $147(11.06)$ & 1.048 & $0.587-1.869$ & $17(8.81)$ \\
\hline IEN/DYS & 1 & $38(4.42)$ & 1.713 & $1.136-2.582$ & 81 (6.09) & 2.261 & $1.212-4.219$ & $17(8.81)$ \\
\hline \multicolumn{9}{|l|}{ Gastric Corpus } \\
\hline Non-AG & 1 & $237(27.56)$ & 0.928 & $0.761-1.130$ & 348 (26.19) & 1.176 & $0.829-1.667$ & 59 (30.57) \\
\hline$A G / I M$ & 1 & $56(6.51)$ & 0.977 & $0.686-1.392$ & $86(6.47)$ & 1.008 & $0.524-1.941$ & $12(6.22)$ \\
\hline IEN/DYS & 1 & $15(1.74)$ & 1.231 & $0.654-2.316$ & $29(2.18)$ & 2.195 & $0.875-5.506$ & $7(3.63)$ \\
\hline \multicolumn{9}{|l|}{ Whole Stomach } \\
\hline Non-AG & 1 & 367 (42.67) & 1.272 & $1.043-1.550$ & $599(45.07)$ & 1.234 & $0.857-1.774$ & $87(45.08)$ \\
\hline$A G / I M$ & 1 & 116 (13.49) & 1.276 & $0.969-1.680$ & $190(14.30)$ & 1.032 & $0.609-1.748$ & 23 (11.92) \\
\hline IEN/DYS & 1 & $58(6.74)$ & 1.693 & $1.199-2.390$ & $126(9.48)$ & 2.153 & $1.241-3.737$ & $24(12.44)$ \\
\hline
\end{tabular}

Reference group: normal group

Abbreviations: AG atrophic gastritis, IM intestinal metaplasia, IEN intraepithelial neoplasia, DYS dysplasia, GC gastric cancer

by sex, age, HP, smoking, drinking, high-salt diet, and tea consumption (Table 7).

\section{Discussion}

In our study, it was found that people with FDR-GC and FDR-nGC were related to the precursors of GC closely. In addition, the younger the age at which FDRs were diagnosed with GC, the more likely the participants were to suffer from atrophic gastritis/intestinal metaplasia.

Table 4 Adjusted odds ratios of whole stomach, gastric antrum and gastric corpus specific GC precursors associated with family history of gastric cancer and of cancers other than gastric

\begin{tabular}{|c|c|c|c|c|c|}
\hline \multirow{2}{*}{$\begin{array}{l}\text { Exposure of interest } \\
\text { Outcome }\end{array}$} & \multirow{2}{*}{$\begin{array}{l}\text { FDR-nC } \\
\text { aOR }\end{array}$} & \multicolumn{2}{|c|}{ FDR-GC } & \multicolumn{2}{|c|}{ FDR-nGC } \\
\hline & & aOR & $95 \% \mathrm{Cl}$ & aOR & $95 \% \mathrm{Cl}$ \\
\hline \multicolumn{6}{|l|}{ Gastric Antrum } \\
\hline Non-AG & 1 & 1.351 & $1.101-1.657$ & 1.184 & $0.822-1.704$ \\
\hline$A G / I M$ & 1 & 1.426 & $1.038-1.959$ & 1.020 & $0.563-1.848$ \\
\hline IEN/DYS & 1 & 1.645 & $1.077-2.511$ & 2.113 & $1.120-3.988$ \\
\hline \multicolumn{6}{|l|}{ Gastric Corpus } \\
\hline Non-AG & 1 & 0.856 & $0.693-1.056$ & 1.162 & $0.806-1.674$ \\
\hline$A G / I M$ & 1 & 0.954 & $0.662-1.374$ & 0.960 & $0.495-1.864$ \\
\hline IEN/DYS & 1 & 1.219 & $0.634-2.343$ & 1.926 & $0.753-4.925$ \\
\hline \multicolumn{6}{|l|}{ Whole Stomach } \\
\hline Non-AG & 1 & 1.171 & $0.946-1.451$ & 1.208 & $0.824-1.773$ \\
\hline$A G / I M$ & 1 & 1.284 & $0.961-1.716$ & 1.008 & $0.586-1.734$ \\
\hline IEN/DYS & 1 & 1.655 & $1.153-2.376$ & 1.984 & $1.122-3.506$ \\
\hline
\end{tabular}

Reference group: normal group

OR was adjusted by gender, age, HP, smoking, drinking, high-salt diet, and tea consumption

Abbreviations: $A G$ atrophic gastritis, IM intestinal metaplasia, IEN intraepithelial neoplasia, DYS dysplasia, GC gastric cancer, $a O R$ adjusted $O R$
Table 5 Influence of age at diagnosis with GC of first-degree relatives on participants' gastric pathology

\begin{tabular}{clllll}
\hline & $\mathbf{N}$ & OR & $\mathbf{9 5 \%} \mathbf{C l}$ & OR $^{\mathbf{a}}$ & $\mathbf{9 5 \% C l}$ \\
\hline Non-AG & & & & & \\
$<50$ & $40 / 73$ & 1.905 & $0.894-4.057$ & 2.185 & $0.965-4.950$ \\
$\geq 50$ & $102 / 230$ & 1.026 & $0.587-1.793$ & 1.098 & $0.598-2.017$ \\
$\geq 60$ & $159 / 353$ & 1.092 & $0.643-1.855$ & 1.202 & $0.674-2.145$ \\
$\geq 70$ & $114 / 262$ & 0.969 & $0.561-1.675$ & 1.210 & $0.666-2.198$ \\
$\geq 80$ & $41 / 87$ & 1 & & 1 & \\
AG/IM & & & & & \\
$<50$ & $11 / 73$ & 3.667 & $1.136-11.838$ & 4.921 & $1.439-16.832$ \\
$\geq 50$ & $40 / 230$ & 2.817 & $1.080-7.345$ & 3.410 & $1.256-9.257$ \\
$\geq 60$ & $54 / 353$ & 2.596 & $1.018-6.621$ & 3.239 & $1.222-8.582$ \\
$\geq 70$ & $35 / 262$ & 2.083 & $0.797-5.447$ & 2.898 & $1.065-7.887$ \\
$\geq 80$ & $6 / 87$ & 1 & & 1 & \\
IEN/DYS & & & & & \\
$<50$ & $7 / 73$ & 1.556 & $0.485-4.992$ & 2.372 & $0.692-8.130$ \\
$\geq 50$ & $17 / 230$ & 0.798 & $0.320-1.990$ & 1.039 & $0.398-2.711$ \\
$\geq 60$ & $36 / 353$ & 1.154 & $0.500-2.661$ & 1.517 & $0.631-3.650$ \\
$\geq 70$ & $29 / 262$ & 1.151 & $0.489-2.709$ & 1.578 & $0.639-3.893$ \\
$\geq 80$ & $9 / 87$ & 1 & & 1 & \\
\hline
\end{tabular}

Reference group: normal group

The age of people in this study was between 26 and 88

adjusted by gender, age, HP, smoking, drinking, high-salt diet, and tea consumption.

Abbreviations: AG atrophic gastritis, IM intestinal metaplasia, IEN intraepithelial neoplasia, DYS dysplasia, GC gastric cancer 
Table 6 Influence of participant with FDR-GC of father, mother, and sibling on gastric pathology, respectively

\begin{tabular}{|c|c|c|c|c|c|c|c|c|}
\hline & \multicolumn{3}{|l|}{ FDR-GC } & \multicolumn{2}{|l|}{ FDR-nC } & \multicolumn{2}{|c|}{ FDR-GC } & \multirow{2}{*}{$\begin{array}{l}\text { FDR-nC } \\
\text { OR }\end{array}$} \\
\hline & $\mathrm{N}$ & OR & $95 \% \mathrm{Cl}$ & $\mathrm{N}$ & $\overline{O R}$ & $\overline{O^{a}}$ & $95 \% \mathrm{Cl}$ & \\
\hline \multicolumn{9}{|l|}{ Father } \\
\hline Non-AG & $292 / 669$ & 1.136 & $0.901-1.433$ & $367 / 848$ & 1 & 1.007 & $0.778-1.305$ & 1 \\
\hline$A G / I M$ & $99 / 669$ & 1.219 & $0.885-1.678$ & $116 / 848$ & 1 & 1.296 & $0.916-1.834$ & 1 \\
\hline IEN/DYS & $63 / 669$ & 1.551 & $1.043-2.307$ & $58 / 848$ & 1 & 1.573 & $1.024-2.417$ & 1 \\
\hline \multicolumn{9}{|l|}{ Mother } \\
\hline Non-AG & $114 / 235$ & 1.490 & $1.059-2.097$ & $367 / 848$ & 1 & 1.312 & $0.902-1.907$ & 1 \\
\hline$A G / I M$ & $33 / 235$ & 1.365 & $0.852-2.186$ & $116 / 848$ & 1 & 1.430 & $0.872-2.345$ & 1 \\
\hline IEN/DYS & $24 / 235$ & 1.985 & $1.149-3.429$ & $58 / 848$ & 1 & 1.988 & $1.116-3.542$ & 1 \\
\hline \multicolumn{9}{|l|}{ Sibling } \\
\hline Non-AG & $67 / 142$ & 1.437 & $0.942-2.193$ & $367 / 848$ & 1 & 1.274 & $0.809-2.006$ & 1 \\
\hline$A G / I M$ & $23 / 142$ & 1.561 & $0.893-2.726$ & $116 / 848$ & 1 & 1.378 & $0.770-2.464$ & 1 \\
\hline IEN/DYS & $13 / 142$ & 1.764 & $0.887-3.509$ & $58 / 848$ & 1 & 1.542 & $0.763-3.117$ & 1 \\
\hline
\end{tabular}

Reference group: normal group

adjusted by gender, age, HP, smoking, drinking, high-salt diet, and tea consumption.

Abbreviations: $A G$ atrophic gastritis, IM intestinal metaplasia, IEN intraepithelial neoplasia, DYS dysplasia, GC gastric cancer

The risk of non-atrophic gastritis, atrophic gastritis/intestinal metaplasia, and intraepithelial neoplasia/dysplasia was also higher in participants with the FDR-GC who was the mother than in those with the FDR-GC who was the father or sibling.

Many studies have reported that GC has an underlying genetic predisposition [22, 23]. The risk of GC in migrants is similar to that in native people, but does not approach that in people in the first generation post-migration [24]. In a study of 4282 patients diagnosed with GC, Kwak [25] found that the average age at GC diagnosis in patients with paternal FDR-GC was significantly lower than that in those without FDR-GC $(54.4 \pm 10.4$ vs. $58.1 \pm 12.0, P<$ 0.001). Therefore, many studies have confirmed that people with FDR-GC are at a high risk of GC [26, 27]. In addition, people with precursors of GC such as atrophic

Table 7 Influence of participant with one or more FDR-GC on gastric pathology

\begin{tabular}{|c|c|c|c|}
\hline & \multicolumn{2}{|c|}{$\geq 2$ FDR-GC } & \multirow{2}{*}{$\begin{array}{l}\text { Single FDR-GC } \\
\text { OR }\end{array}$} \\
\hline & OR & $95 \% \mathrm{Cl}$ & \\
\hline Non-AG & 1.518 & $0.869-2.654$ & 1 \\
\hline AG/IM & 1.188 & $0.552-2.558$ & 1 \\
\hline IEN/DYS & 1.339 & $0.569-3.152$ & 1 \\
\hline Non- $A G^{a}$ & 1.700 & $0.940-3.074$ & 1 \\
\hline$A G / M^{a}$ & 1.291 & $0.579-2.877$ & 1 \\
\hline IEN/DYS ${ }^{a}$ & 1.265 & $0.517-3.096$ & 1 \\
\hline
\end{tabular}

Reference group: normal group

adjusted by gender, age, HP, smoking, drinking, high-salt diet, and tea consumption.

Abbreviations: AG atrophic gastritis, IM intestinal metaplasia, IEN intraepithelial neoplasia, DYS dysplasia, GC gastric cancer gastritis and intestinal metaplasia on gastroendoscopy, had a significant risk of $\mathrm{GC}[15,28]$. However, the relationship between the family history of GC and GC precursors is rarely reported in detail. Therefore, this study was performed to screen for GC in high-risk groups.

In this study, it was found that people with FDR-GC were more likely to suffer from atrophic gastritis/intestinal metaplasia and intraepithelial neoplasia/dysplasia than people with FDR-nC, which is consistent with findings of previous studies [29, 30]. El-Omar et al. [31] reported that people in Scotland with FDR-GC had a higher prevalence of atrophic gastritis (34\% vs. 5\%) and intestinal metaplasia (19\% vs. $12 \%$ ) than people with FDR-nC. Meanwhile, we found that the gastric antrum was more prone to developing atrophic gastritis/intestinal metaplasia and intraepithelial neoplasia/dysplasia than the gastric corpus, and was more susceptible to FDR-GC. In addition, Gonzalez found that patients with atrophic gastritis and intestinal metaplasia are more likely to develop GC, especially in those with a family history of GC [32]. Therefore, people with FDR-GC require more intensive surveillance, with a particular focus on the gastric antrum.

In our study, none of the participants with FDR-nGC were diagnosed with GC. Song et al. found that except for a family history of breast cancer as a risk factor for GC, people with FDR-nGC did not have a significant increase in the risk of GC [14]. Foschi [33] and Dhillon [34] reported that the family history of non-gastric cancer was not an independent influential factor of GC, and our results were in accordance with these studies. Meanwhile, participants with FDR-nGC did not have an increased risk of non-atrophic gastritis and atrophic 
gastritis/intestinal metaplasia but were more likely to suffer from intraepithelial neoplasia/dysplasia than those with FDR-nC in our study. This may be the result of a combination of genetic and environmental factors [15]. Some studies reported that there was a tendency for the risks of GC to be above unity for a family history of cancer including cancers of the oesophagus, colorectum, liver, gallbladder, and pancreas, while none of the estimates were significant, and the relative risk of a family history of lung cancer was 1.5 for stomach cancer $(95 \%$ CI $1.0-2.3)$ [14, 35, 36]. Meanwhile, some genes play a role not only in GC but also in breast cancer [35, 37, 38]. Therefore, we must cautiously report that having FDR-nGC was a risk factor for intraepithelial neoplasia/dysplasia.

In this study, we found that the participants were associated with atrophic gastritis/intestinal metaplasia closely if their FDRs were diagnosed with GC at a younger age. In an American study [39], 19\% of people under the age of 40 years who were diagnosed with GC had a positive family history, with the intestinal type of GC being the most common type [40], while western series reported a positive family history in less than $10 \%$ of individuals. $\mathrm{Yu}$ Bai reported that patients who were diagnosed with GC before the age of 35 years had a higher frequency of family history of GC (19\%) with fewer alarming features [41]. These results suggest that the younger the age at diagnosis, the greater the influence family history may have on that individual. When an individual has an FDR diagnosed with GC at a young age, gastroendoscopy should be performed earlier in that individual.

In our study, participants whose FDR-GC was the mother had a higher risk of developing non-atrophic gastritis, atrophic gastritis/intestinal metaplasia, and intraepithelial neoplasia/dysplasia than those whose FDR-GC was the father or sibling. Palli reported that subjects were at a higher risk of GC with a maternal FDR-GC than with a paternal FDR-GC [42]. Zhou et al. suggested that a certain subtype of GC may be inherited in a female-influenced fashion [43]. However, Song et al. $[13,14]$ reported that compared with that of parents, the gastric pathology of siblings was more closely related to the gastric pathology of patients. Although studies of the impact of a sibling or parent FDR-GC on GC development have reported discrepant results, it was consistently reported that people with a maternal FDR-GC were more likely to develop GC than those with a paternal FDR-GC [44]. In addition, there was no statistically significant difference in non-atrophic gastritis, atrophic gastritis/intestinal metaplasia, and intraepithelial neoplasia/dysplasia between participants with one or more FDR-GC, and Bernini [45] reported that the number of FDR-GC did not affect the risk of GC.

The advantages of this study are obvious. Our study is novel in that few studies have reported the relationship between family history and GC precursors in detail. Additionally, our study had a large sample size with an asymptomatic population, which ensures the stability of the results. Furthermore, in people with or without a family history, 32 patients with GC were detected, most of whom were in early stages of GC (71.9\%), which reflects the social benefits of this study. In addition, the structured interview-administered questionnaire concerning the patient's family history was completed under the guidance of physicians, and Bravi et al. found that such a questionnaire was relatively reliable for data on family history of all cancers [46]. However, our study has many disadvantages. One of the limitations was that only 2382 of 3439 (69.26\%) participants eventually underwent gastroendoscopy. This may have led to a potential bias. Analogously, in a Korean study, they found that people with or without a family history of GC were not all willing to undergo gastroendoscopy screening (39.2 and $32.3 \%$, respectively) [47].

In further studies, we will increase the number of participants with FDR-GC to explore the detection rate of GC, especially early GC, in high-risk groups compared to the normal population. In addition, we believe that family history of first-degree relatives should be paid close attention to when screening for gastric cancer, so as to identify high-risk groups more accurately and improve the detection rate of precursors of GC and GC.

\section{Conclusion}

People with FDR-GC are at a high risk of intraepithelial neoplasia/dysplasia. The younger the age at which FDRs were diagnosed with GC, the more likely the participants were to develop AG/IM. The risk of non-atrophic gastritis, atrophic gastritis/intestinal metaplasia, and intraepithelial neoplasia/dysplasia was also higher in participants with an FDR-GC who was the mother than in those with an FDR-GC who was the father or sibling. There was no statistically significant difference in the GC precursors between participants with one or more FDR-GC.

\section{Abbreviations \\ AG: Atrophic gastritis; Cl: Confidence interval; DYS: Dysplasia; FDR: First- degree relative; GC: Gastric cancer; IEN: Intraepithelial neoplasia; IM: Intestinal metaplasia; OR: Odds ratio; PG: Pepsinogen}

\section{Acknowledgements}

We would like to thank Wiley Editing Services for English language editing.

\section{Authors' contributions}

$Z Q, Y C, J L, F Z N$, and WR were involved in the manuscript conception and preparation; WR, JL, YC, and TYW collected and analyzed the data; WR, TYW, FZN carried out the statistical analysis; WR, YC, JL, TYW, and ZQ performed the manuscript writing; All authors had final approval of the submitted version. 


\section{Funding}

This work was supported by Youth Fund Project of Jiangsu Natural Science Foundation (Grant No. BK20170213), Key young medical talents in Wuxi (No. QNRC062), Wuxi medical innovation team (No. CXTD005). These fundings support the editing and publishing of articles.

\section{Availability of data and materials}

Reasonable requests for data and materials will be considered and should be made in writing to the corresponding author.

\section{Ethics approval and consent to participate}

The study was approved by Ethics Committee of Wuxi People's Hospital. All participants provided written consent.

\section{Consent for publication}

Not applicable.

\section{Competing interests}

The authors declare that they have no competing interests.

\section{Author details}

'Department of Gastroenterology, The Affiliated Wuxi People's Hospital to Nanjing Medical University, 299 Qingyang Road, Wuxi 214023, Jiangsu, China. ${ }^{2}$ Department of Digestive Endoscopy, The First Affiliated Hospital with Nanjing Medical University, 300 Guangzhou Road, Nanjing 210029, Jiangsu, China.

Received: 22 April 2020 Accepted: 3 November 2020 Published online: 16 November 2020

\section{References}

1. Fitzmaurice C, Allen C, Barber RM, Barregard L, Bhutta ZA, Brenner H, Dicker DJ, Chimed-Orchir O, Dandona R, Dandona L, et al. Global, regional, and National Cancer Incidence, mortality, years of life lost, years lived with disability, and disability-adjusted life-years for 32 Cancer groups, 1990 to 2015: a systematic analysis for the global burden of disease study. JAMA ONCOL. 2017;3(4):524-48.

2. Bray F, Ferlay J, Soerjomataram I, Siegel RL, Torre LA, Jemal A. Global cancer statistics 2018: GLOBOCAN estimates of incidence and mortality worldwide for 36 cancers in 185 countries. CA Cancer J Clin. 2018;68(6):394-424.

3. Thrift AP, El-Serag HB. Burden of gastric Cancer. Clin Gastroenterol Hepatol. 2020:18(3):534-42

4. van der Kaaij RT, Koemans WJ, van Putten M, Snaebjornsson P, Luijten J, van Dieren JM, Cats A, Lemmens V, Verhoeven R, van Sandick JW. A populationbased study on intestinal and diffuse type adenocarcinoma of the oesophagus and stomach in the Netherlands between 1989 and 2015. Eur J Cancer. 2020;130:23-31.

5. Xiao D, Tong X, Yuan X, Wu Y, Chen P. Gastric xanthelasma may be a warning sign of intestinal metaplasia: a crosssectional study. Oncol Rep. 2020;44(3):1275-81.

6. Gong EJ, Ahn JY, Jung HY, Lim H, Choi KS, Lee JH, Kim DH, Choi KD, Song $\mathrm{HJ}$, Lee $\mathrm{GH}$, et al. Risk factors and clinical outcomes of gastric cancer identified by screening endoscopy: a case-control study. J Gastroenterol Hepatol. 2014;29(2):301-9.

7. Jun JK, Choi KS, Lee HY, Suh M, Park B, Song SH, Jung KW, Lee CW, Choi IJ, Park EC, et al. Effectiveness of the Korean National Cancer Screening Program in reducing gastric Cancer mortality. Gastroenterology. 2017;152(6): 1319-28.

8. Hamashima C, Ogoshi K, Okamoto M, Shabana M, Kishimoto T, Fukao A. A community-based, case-control study evaluating mortality reduction from gastric cancer by endoscopic screening in Japan. PLoS One. 2013;8(11): e79088.

9. Chen Q, Yu L, Hao CQ, Wang JW, Liu SZ, Zhang M, Zhang SK, Guo LW, Quan PL, Zhao N, et al. Effectiveness of endoscopic gastric cancer screening in a rural area of Linzhou, China: results from a case-control study. Cancer Med. 2016:5(9):2615-22.

10. Ji L, Liu Z, Zhou B, Cai Y, An F, Wang L, Lv Z, Xia M, Yang J, Yuan J, et al. Community-based pilot study of a screening program for gastric Cancer in a Chinese population. Cancer Prev Res (Phila). 2020;13(1):73-82.
11. Kim GH, Liang PS, Bang SJ, Hwang JH. Screening and surveillance for gastric cancer in the United States: is it needed? Gastrointest Endosc. 2016;84(1): 18-28.

12. Rugge M, Genta RM, Di Mario F, El-Omar EM, El-Serag HB, Fassan M, Hunt $\mathrm{RH}$, Kuipers EJ, Malfertheiner P, Sugano K, et al. Gastric Cancer as preventable disease. Clin Gastroenterol Hepatol. 2017;15(12):1833-43.

13. Song H, Ekheden IG, Ploner A, Ericsson J, Nyren O, Ye W. Family history of gastric mucosal abnormality and the risk of gastric cancer: a populationbased observational study. Int J Epidemiol. 2018;47(2):440-9.

14. Song M, Camargo MC, Weinstein SJ, Best AF, Mannisto S, Albanes D, Rabkin CS. Family history of cancer in first-degree relatives and risk of gastric cancer and its precursors in a Western population. Gastric Cancer. 2018; 21(5):729-37.

15. Banks M, Graham D, Jansen M, Gotoda T, Coda S, di Pietro M, Uedo N, Bhandari P, Pritchard DM, Kuipers EJ, et al. British Society of Gastroenterology guidelines on the diagnosis and management of patients at risk of gastric adenocarcinoma. GUT. 2019;68(9):1545-75.

16. Shao L, Li P, Ye J, Chen J, Han Y, Cai J, Lu X. Risk of gastric cancer among patients with gastric intestinal metaplasia. Int J Cancer. 2018;143(7):1671-7.

17. Schonberg MA, Breslau ES, McCarthy EP. Targeting of mammography screening according to life expectancy in women aged 75 and older. J Am Geriatr Soc. 2013;61(3):388-95.

18. Hahm Ml, Choi KS, Lee HY, Jun JK, Oh D, Park EC. Who participates in the gastric cancer screening and on-time rescreening in the National Cancer Screening Program? A population-based study in Korea. Cancer Sci. 2011; 102(12):2241-7.

19. Tu H, Sun L, Dong X, Gong Y, Xu Q, Jing J, Yuan Y. Serum anti-helicobacter pylori immunoglobulin $\mathrm{G}$ titer correlates with grade of histological gastritis, mucosal bacterial density, and levels of serum biomarkers. Scand J Gastroenterol. 2014:49(3):259-66.

20. Dixon MF, Genta RM, Yardley JH, Correa P. Classification and grading of gastritis. The updated Sydney system. International workshop on the histopathology of gastritis, Houston. AM J SURG PATHOL 1996. 1994;20(10): 1161-81.

21. Price AB. The Sydney system: histological division. J Gastroenterol Hepatol. 1991:6(3):209-22.

22. Stoffel EM. Heritable gastrointestinal Cancer syndromes. Gastroenterol Clin N Am. 2016:45(3):509-27.

23. Lott PC, Carvajal-Carmona LG. Resolving gastric cancer aetiology: an update in genetic predisposition. Lancet Gastroenterol Hepatol. 2018:3(12):874-83.

24. Yaghoobi M, Bijarchi $R$, Narod SA. Family history and the risk of gastric cancer. Br J Cancer. 2010;102(2):237-42.

25. Kwak HW, Choi IJ, Kim CG, Lee JY, Cho SJ, Eom BW, Yoon HM, Joo J, Ryu KW, Kim YW. Individual having a parent with early-onset gastric cancer may need screening at younger age. World J Gastroenterol. 2015;21(15):4592-8.

26. Dong E, Duan L, Wu BU. Racial and ethnic minorities at increased risk for gastric Cancer in a regional US population study. Clin Gastroenterol Hepatol. 2017;15(4):511-7.

27. Wei $X L$, Qiu MZ, Jin Y, Huang YX, Wang RY, Chen WW, Wang DS, Wang F, Luo HY, Zhang DS, et al. Hepatitis B virus infection is associated with gastric cancer in China: an endemic area of both diseases. Br J Cancer. 2015;112(7): 1283-90.

28. Choi AY, Strate LL, Fix MC, Schmidt RA, Ende AR, Yeh MM, Inadomi JM, Hwang $\mathrm{JH}$. Association of gastric intestinal metaplasia and east Asian ethnicity with the risk of gastric adenocarcinoma in a U.S. population. Gastrointest Endosc. 2018;87(4):1023-8.

29. You WC, Ma JL, Liu W, Gail MH, Chang YS, Zhang L, Hu YR, Fraumeni JJ, Xu GW. Blood type and family cancer history in relation to precancerous gastric lesions. Int J Epidemiol. 2000;29(3):405-7.

30. Motta CR, Cunha MP, Queiroz DM, Cruz FW, Guerra EJ, Mota RM, Braga LL. Gastric precancerous lesions and helicobacter pylori infection in relatives of gastric cancer patients from northeastern Brazil. DIGESTION. 2008;78(1):3-8.

31. El-Omar EM, Oien K, Murray LS, El-Nujumi A, Wirz A, Gillen D, Williams C, Fullarton G, McColl KE. Increased prevalence of precancerous changes in relatives of gastric cancer patients: critical role of $\mathrm{H}$. pylori. GAST ROENTEROLOGY. 2000;118(1):22-30

32. Gonzalez CA, Pardo ML, Liso JM, Alonso P, Bonet C, Garcia RM, Sala N, Capella G, Sanz-Anquela JM. Gastric cancer occurrence in preneoplastic lesions: a long-term follow-up in a high-risk area in Spain. Int J Cancer. 2010; 127(11):2654-60 
33. Foschi R, Lucenteforte E, Bosetti C, Bertuccio P, Tavani A, La Vecchia C, Negri E. Family history of cancer and stomach cancer risk. Int J Cancer. 2008; 123(6):1429-32.

34. Dhillon PK, Farrow DC, Vaughan TL, Chow WH, Risch HA, Gammon MD, Mayne ST, Stanford JL, Schoenberg JB, Ahsan H, et al. Family history of cancer and risk of esophageal and gastric cancers in the United States. Int J Cancer. 2001;93(1):148-52.

35. Guilford PJ, Hopkins JB, Grady WM, Markowitz SD, Willis J, Lynch H, Rajput A, Wiesner $\mathrm{GL}$, Lindor NM, Burgart $L$, et al. E-cadherin germline mutations define an inherited cancer syndrome dominated by diffuse gastric cancer. Hum Mutat. 1999;14(3):249-55.

36. La Vecchia C, Negri E, Franceschi S, Gentile A. Family history and the risk of stomach and colorectal cancer. CANCER-AM CANCER SOC. 1992;70(1):50-5.

37. Benusiglio PR, Malka D, Rouleau E, De Pauw A, Buecher B, Nogues C, Fourme $\mathrm{E}$, Colas $\mathrm{C}$, Coulet $\mathrm{F}$, Warcoin $\mathrm{M}$, et al. $\mathrm{CDH1}$ germline mutations and the hereditary diffuse gastric and lobular breast cancer syndrome: a multicentre study. J Med Genet. 2013;50(7):486-9.

38. Chikman B, Davidson T, Kais H, Jeroukhimov I, Leshno A, Sandbank J, Halevy A, Lavy R. Is there an association between invasive lobular carcinoma of the breast and a family history of gastric cancer? Familial Cancer. 2016;15(1):41-7.

39. Koea JB, Karpeh MS, Brennan MF. Gastric cancer in young patients: demographic, clinicopathological, and prognostic factors in 92 patients. Ann Surg Oncol. 2000;7(5):346-51.

40. Eto K, Ohyama S, Yamaguchi T, Wada T, Suzuki Y, Mitsumori N, Kashiwagi H, Anazawa S, Yanaga K, Urashima M. Familial clustering in subgroups of gastric cancer stratified by histology, age group and location. Eur J Surg Oncol. 2006;32(7):743-8,

41. Bai Y, Li ZS. Endoscopic, clinicopathological features and prognosis of very young patients with gastric cancer. J Gastroenterol Hepatol. 2011;26(11): 1626-9.

42. Palli D, Galli M, Caporaso NE, Cipriani F, Decarli A, Saieva C, Fraumeni JJ, Buiatti E. Family history and risk of stomach cancer in Italy. Cancer Epidemiol Biomark Prev. 1994;3(1):15-8.

43. Zhou XF, He YL, Song W, Peng JJ, Zhang CH, Li W, Wu H. Comparison of patients by family history with gastric and non-gastric cancer. World J Gastroenterol. 2009;15(21):2644-50.

44. Choi YJ, Kim N. Gastric cancer and family history. KOREAN J INTERN MED. 2016;31(6):1042-53.

45. Bernini M, Barbi S, Roviello F, Scarpa A, Moore P, Pedrazzani C, Beghelli S, Marrelli D, de Manzoni G. Family history of gastric cancer: a correlation between epidemiologic findings and clinical data. Gastric Cancer. 2006;9(1): 9-13.

46. Bravi F, Bosetti C, Negri E, Lagiou P, La Vecchia C. Family history of cancer provided by hospital controls was satisfactorily reliable. J Clin Epidemiol. 2007;60(2):171-5.

47. Kang JM, Shin DW, Kwon YM, Park SM, Park MS, Park JH, Son KY, Cho BL. Stomach cancer screening and preventive behaviors in relatives of gastric cancer patients. World J Gastroenterol. 2011;17(30):3518-25.

\section{Publisher's Note}

Springer Nature remains neutral with regard to jurisdictional claims in published maps and institutional affiliations.

\section{Ready to submit your research? Choose BMC and benefit from:}

- fast, convenient online submission

- thorough peer review by experienced researchers in your field

- rapid publication on acceptance

- support for research data, including large and complex data types

- gold Open Access which fosters wider collaboration and increased citations

- maximum visibility for your research: over $100 \mathrm{M}$ website views per year

At $\mathrm{BMC}$, research is always in progress.

Learn more biomedcentral.com/submissions 